\title{
Early identification of cooperative fragments for protein-protein interaction stabilization
}

\author{
Pim J. de Vink‡, Peter J. Cossarł, Bente A. Somsen, Christian Ottmann, Luc Brunsveld* \\ Address: Laboratory of Chemical Biology, Institute for Complex Molecular Systems and Department of Biomedical \\ Engineering, Eindhoven University of Technology, P.O. Box 513, Eindhoven, 5600 MB, The Netherlands.
}

Keywords: Protein-Protein Interactions, Fragment-based drug discovery, Saturation transfer difference NMR, cooperativity, molecular glues, 14-3-3

\begin{abstract}
Modulating protein-protein interactions (PPIs) is an effective approach to drug discovery, with several drugs in the clinic that inhibit PPIs. The orthogonal approach of PPI stabilization has developed slowly, a function of the complicated dynamics of multi-component protein complexes. In contrast to PPI inhibition, where ligand affinity is the driving parameter for efficacy, cooperativity is frequently the directing variable for PPI stabilization. Here we show how STD NMR allows for early-stage detection of cooperativity using the hub protein 14-3-3, a focused library of fragments and several 14-3-3 partner proteins. Further, we validate that the observed enhancement in STD signal is a function of cooperativity of the ternary 14-3-3 complex, using mutagenesis and X-ray crystallography. Additionally, we assess the differential cooperativity of three fragments in a panel of 14-3-3 interaction partners. Finally, we demonstrate how selective 14-3-3 complex formation is a function of cooperativity effects
\end{abstract}

\section{Manuscript}

Stabilization of protein-protein interactions (PPIs) with small molecules is an emergent strategy in drug discovery with the potential to target 'hard to drug' protein classes'. PPI stabilizers, such as molecular glues, enhance the affinity of a protein complex through a cooperativity mechanism. Cooperativity is a common phenomenon in complex biological systems, where an initial binding event enhances the affinity of subsequent binding events ${ }^{2,3}$. Both synthetic PPI stabilizers, like Pleconaril and Tafamidis, as well as natural products, have shown remarkable target selectivity, with Rapamycin and Taxol used in the clinic for decades. Despite these successes, molecular glues remain challenging to design de novo, with the vast majority discovered retrospectively 4 . Notable exceptions are bifunctional compounds such as PROteolysis-TArgeting Chimeras (PROTACs) ${ }^{5,6}$. This approach to targeted protein degradation is partly converging with PPI stabilization towards more cooperative compounds ${ }^{7}$.

A significant challenge for the (early stage) discovery of new cooperative compounds is the complicated dynamics of multi-component complexes of proteins and small molecules. Not only is the affinity of a compound important, but cooperativity is similarly critical to protein complex stabilization. This requires hit compounds in a screening campaign to pass through a double selection filter of occupancy (affinity) and ability to induce stabilization (cooperativity) to elicit an assay response. This combination of criteria is particularly challenging to meet for screening libraries, given the weak affinities of initial PPI stabilizer hits, and is further amplified for fragment screens ${ }^{8}$.

To circumvent the challenges of identifying low affinity chemical matter, covalent fragment approaches have been developed $^{9}$. Covalent tethering typically employs a reactive group that anchors a fragment on a protein surface ${ }^{10}$. Our laboratory and others have further developed this approach for PPI stabilization. Specifically focusing on reversible covalent tethering approaches that exploit disulfide ${ }^{11}$ and imine chemistry ${ }^{12}$ to anchor the fragments at the PPI interface. Notwithstanding, removal or substitution of the reactive group remains challenging due to molecular recognition of the fragment being dependent on the reactive group or the specific molecular orientation induced by the covalent linker ${ }^{13}$. Therefore, non-covalent fragment libraries also have significant value, given hit detection is dominated by molecular recognition ${ }^{14}$.

Fragment-based drug discovery has proven to produce clinical candidates via fragment growth, linking, merging or self-assembly strategies using non-covalent fragments as initial starting points ${ }^{15}$; and provides a solid foundation of 
medicinal chemistry principles to improve ligand potency ${ }^{16,17}$. In contrast, our understanding of optimizing cooperativity is still developing 18,19 . Therefore, biophysical approaches to detect cooperativity at the early stages of hit identification are urgently needed.

Most standard biophysical screening techniques, such as Fluorescence Anisotropy (FA), Förster Resonance Energy Transfer, Isothermal Calorimetry, and Surface Plasmon Resonance, are optimized to detect relatively strong binding interactions. The affinity detection windows of these techniques are less suited for initial PPI stabilizer hit identification, especially of the fragment-type ${ }^{20,21}$. Further, many fluorescent biophysical assays have an indirect output which can decrease the observed cooperativity in these assays ${ }^{2}$. Also, certain fragments (termed silent binders) can form ternary complexes in X-ray crystallography, while having no effect in solution-based assays ${ }^{12}$. There is a significant need to develop assays to identify cooperativity that function at the low millimolar range to detect early PPI stabilizer chemical matter.

Saturation Transfer Difference (STD) NMR, waterLOGSY22 and ${ }^{19} \mathrm{~F}$ NMR can be used to detect millimolar potent fragments ${ }^{23,24}$. STD NMR has been used for example successfully to observe allosteric cooperativity for GPCRs ${ }^{25,26}$. Furthermore, STD NMR is ligand-observed and measures the binding event of the ligand directly. Also, within the STD NMR assay format PPI partners can be combined at concentrations that allow for high binary PPI occupancy. NMR is thus well suited to measure the weak affinities associated with fragments ${ }^{27}$, monitoring ligand binding from the preformed binary PPI complex.

Utilizing 14-3-3 and a panel of its phosphorylated partner peptides as a case study, we characterize early stage cooperativity in fragment binding using STD NMR. 14-3-3 proteins are involved in numerous cellular functions, including scaffolding, nuclear occlusion and signal transduction ${ }^{28}$. The protein typically binds disordered regions of phosphorylated partners via conserved phorphorylated serine or thrionine epitopes ${ }^{29}$. Given the extensive 14-3-3 proteome, consisting of hundreds of binding partners, stabilization of a specific PPI is crucial for therapeutic benefits. We demonstrate that 14-3-3 complex stabilization can be detected at low mM concentration using STD NMR. We also show that differential cooperativity influences the selectivity of complex formation, leading to early-stage detection of selective complex formation.

Previously, using X-ray crystallography, we identified that amidine substituted thiophenes and benzothiophenes bind into the phosphopeptide-binding-groove of 14-3-3, adjacent to the TAZ phosphopeptide (Fig. 1a) ${ }^{30}$. The amidine moiety of AZ130, which is essential for activity in this class of compounds, forms a salt bridge with E14 of 14-3-3 $\sigma$. However, AZ130 has no enhancing effect on the 14-3-3:TAZ interaction in FA assays. Utilizing AZ130 as a model fragment, we sought to investigate the binding of AZ130 with and without the TAZ peptide to assess the capacity of STD NMR to detect cooperative fragment binding (Fig. 1b). In STD NMR, the receptor protein and peptide are selectively presaturated to suppress their signals. ${ }^{23}$ This pre-saturation is transferred to binding fragments resulting in a decrease of the signals associated with the binding fragment. We propose that synergistic effects of the peptide in the presence of 14-3-3 and the fragment will translate to a more pronounced STD signal for the ligand. Therefore, an STD experiment was performed in the presence and absence of the partner peptide TAZ (10-fold excess). Important to us was the tractability of this methodology for other research groups. We were particularly interested in applying this technique to a conventional $400 \mathrm{MHz}$ NMR machine without the need for a cryoprobe. Screening of AZ130 was conducted on a

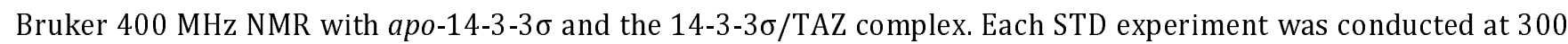
$\mu \mathrm{M}$ of AZ130, $10 \mu \mathrm{M}$ of 14-3-3 $\sigma$ in PBS buffer and $10 \% \mathrm{D}_{2} \mathrm{O}$. Analysis of the STD spectrum of the AZ130 with 14-3-3 $\sigma$ identified two weak proton signals at 7.35 and $7.65 \mathrm{ppm}$, consistent with the protons associated with the phenyl and thiophene rings of AZ130, suggesting that AZ130 shows weak binding to 14-3-3 $\sigma$ alone (Fig. 1c). Analysis of the 14-

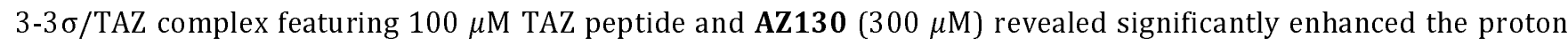
signals, implying cooperative complex formation. This result was consistent with the observed X-ray crystal structure of AZ130 in complex with 14-3-3/TAZ.

Having confirmed the application of STD NMR to detect low affinity fragment binding to the 14-3-3 $\sigma /$ TAZ complex, as well as indications of cooperativity, we investigated a focused library of amidine derivatives (Fig. 2a). The amidine functional group was maintained, given its important electrostatic interaction with 14-3-3 residue E14. Notably, this library elicited no response in a FA assay (Supporting Fig. S1). The focused library was screened using STD NMR against the apo-14-3-3 $\sigma$ protein and the 14-3-3 $\sigma$ /TAZ complex. Analysis of the nine fragments identified that F1, F2, 
F4, F5, F8 and F9 all elicited assay responses. Of these fragments, five bound to apo-14-3-3 (Fig. 2b, Supporting Table S1). Fragments F2, F4, F5 and F9 showed enhanced signals in the presence of the TAZ peptide (see supplementary NMR spectra). F2, F4 and F5 elicited an improved binding of 5.3-, 1.9- and 2.2-fold, respectively, in the presence of TAZ (Fig. 2c \& d). Notably, fragment F9 did not bind to apo-14-3-3; however, a significant signal was observed upon the addition of the TAZ peptide. The fragments F3, F6 and F7, showed no signals for their aromatic protons in either the apo-14-3-3 $\sigma$ or 14-3-3/TAZ complex STD spectra, indicating no fragment binding in either case. A decrease in signal for F1 and $\mathbf{F 8}$ was observed in the presence of TAZ, indicating competition for 14-3-3 biding with TAZ for these fragments (Fig. 2b, c \& e).

We repeated the screen of $\mathbf{F 4}, \mathbf{F 5}$ and $\mathbf{F 9}$ at a higher concentration (5 $\mathrm{mM})$ to validate the initial screening result, using an amplification factor $\left(\mathrm{A}_{\mathrm{STD}}\right)$ as a concentration independent metric. The STD amplification factor was derived by multiplying the relative STD effect ( $I_{\text {on-resonance }} / I_{\text {off-resonance}}$ ) at a fixed fragment concentration where the molar ratio of the fragment is in excess relative to the protein (see supplementary equation 1). Analysis of fragments F4, F5 and F9

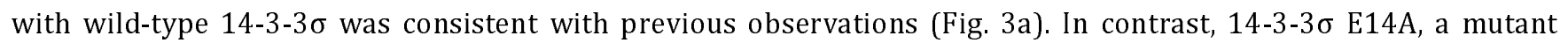
without the crucial glutamic acid, elicited no significant $A_{\text {STD }}$ signal when treated with fragments F4, F5 and F9, neither in the presence nor absence of the TAZ peptide.

Encouraged by these results, we soaked fragments F4, F5 and F9 (at $10 \mathrm{mM}$ ) in preformed TAZ/14-3-3 $\sigma$ crystals. However, we were unable to obtain a structure, likely due to the weak binding affinity requiring high concentrations of the fragment in DMSO. To further validate these results, we soaked the fragments at 10, 20 and 50 mM concentrations into binary crystals of 14-3-3/ER $\alpha$ complex, which tolerate higher concentrations of DMSO ${ }^{31}$. Soaking with 50 mM F9 resulted in a ternary F9/14-3-3/ER $\alpha$ crystal structure at $1.5 \AA \AA$ resolution. Analysis of this co-crystal further confirmed the binding of $\mathbf{F 9}$ at the aforementioned binding site (Fig. 3b, Supporting Fig. S2).

We next assessed the differential cooperativity of fragments F4, F5, and F9 with a panel of other 14-3-3 binding partners. The selected partners encompass structural diversity with some epitopes occupying the complete binding groove and others filling only a part of the binding groove. Fragments F4, F5, and F9 were screened at 5 mM with 100 $\mu \mathrm{M}$ peptide (Fig. 4a). Fragment $\mathbf{F} 4$ results in a high $\mathrm{A}_{\text {STD }}$ signal with most peptide/14-3-3 combinations and appears to be quite promiscuous. In contrast, fragments $\mathbf{F 5}$ and $\mathbf{F 9}$ have a more distinct selectivity profile. F5 showed a preference for ABL1 and RED binding partners. Whilst, F9 elicited a preferred response to TASK3, ABL1 and AS160 (Fig. $4 \mathrm{~b})$.

The selected 14-3-3 binding partners TAZ and ABL1 were used to profile the dose-dependency of fragments F5 and F9 (Fig. 4c). The fragments were titrated to a fixed concentration of 14-3-3 $\sigma$ in the absence or presence of TAZ or ABL1 peptide. In the absence of a peptide only a weak signal increase was observed at higher concentrations, consistent with the fragments having very low affinity to the apo-14-3-3 alone. In contrast, titration of the fragments to a complex of 14-3-3/TAZ or 14-3-3/ABL1 showed a clear dose-response. Fragment F5 elicited a dose-dependent increase in signal with $\mathrm{EC}_{50}$ values of $1.8 \pm 0.4$ and $8.7 \pm 0.4 \mathrm{mM}$ for 14-3-3/TAZ and 14-3-3/ABL1 complexes, respectively. Notably, variations in $\mathrm{A}_{\mathrm{STD}}$ signal intensity are a function of the average number of ligand molecules saturated per 14-3-3 protein. F9 elicited a dose-dependent increase in signal for the 14-3-3/TAZ complex with an $\mathrm{EC}_{50}$ value of $2.3 \pm 0.3 \mathrm{mM}$. Treatment of the 14-3-3/ABL1 complex with F9 resulted in a significant increase in $\mathrm{A}_{\text {STD }}$ Signal. However, no saturation in $A_{\text {STD }}$ signal was observed. Combined, these results suggest that the unique topology and functionality of the composite 14-3-3/partner protein complex drives selectivity through a cooperative mechanism with the ligand binding event.

In summary, we have shown that STD NMR is a valuable screening tool for probing early-stage cooperativity for low affinity fragments, not possible with other biophysical assays. Utilizing this approach, a modest cooperativity effect of the previously termed silent binding AZ130 fragment was determined at high 14-3-3 and TAZ peptide concentrations. This perspective dichotomy between protein and ligand observed assays aligns with thermodynamic models for ternary systems ${ }^{2}$. This study further illustrates how an early focus on cooperativity in the development process can identify selective early stage hit compounds. Further, differential stabilization profiles were observed within our selectivity panel, even for these small fragments. This demonstrates that small structural modifications can significantly affect cooperativity for specific PPI combinations, forming an intriguing entry toward selectivity32. STD-NMR thus presents a powerful and easily accessible tool for the development of molecular glues. It enables direct measurement of fragment signals in the presence and absence of partner proteins. Further, the ubiquitous nature of NMR instru- 
bioRxiv preprint doi: https://doi.org/10.1101/2022.02.23.481635; this version posted February $24,2022$. The copyright holder for this preprint (which was not certified by peer review) is the author/funder, who has granted bioRxiv a license to display the preprint in perpetuity. It is made available under aCC-BY-ND 4.0 International license.

ments, coupled with the technique being not dependent on isotopic enrichment, makes the approach highly amendable to both academic and industrial molecular glue research.

\section{Author Information}

Luc Brunsveld: l.brunsveld@tue.nl

¥These authors contributed equally. The manuscript was written through the contributions of all authors.

L.B. and C.O. are scientific co-founders of Ambagon Therapeutics. The other authors declare no competing financial interests.

\section{Acknowledgements}

This research was funded by the Netherlands Organization for Scientific Research (NWO) through Gravity program (024.001.035), Echo grant (711.017.014) and VICI grant (016.150.366) and by the European Union through the Eurotech Postdoctoral Fellow program (Marie Skłodowska-Curie Co. funded, Grant 754462). Serge Söntjes is kindly acknowledged for assistance with the initial NMR experiments. Xavier Guillory is also thanked for the inspiration for this manuscript.

\section{References}

(1) Schreiber, S. L. The Rise of Molecular Glues. Cell 2021, 184 (1), 3-9. https://doi.org/10.1016/j.cell.2020.12.020.

(2) de Vink, P. J.; Andrei, S. A.; Higuchi, Y.; Ottmann, C.; Milroy, L.-G.; Brunsveld, L. Cooperativity Basis for SmallMolecule Stabilization of Protein-Protein Interactions. Chem. Sci. 2019, 10, 2869-2874. https://doi.org/10.1039/C8SC05242E.

(3) Whitty, A. Cooperativity and Biological Complexity. Nat. Chem. Biol. 2008, 4 (8), 435-439. https://doi.org/10.1038/nchembio0808-435.

(4) Andrei, S. A.; Sijbesma, E.; Hann, M.; Davis, J.; O'Mahony, G.; Perry, M. W. D.; Karawajczyk, A.; Eickhoff, J.; Brunsveld, L.; Doveston, R. G.; Milroy, L.-G.; Ottmann, C. Stabilization of Protein-Protein Interactions in Drug Discovery. Expert Opin. Drug Discov. 2017, 12 (9), 925-940. https://doi.org/10.1080/17460441.2017.1346608.

(5) Lai, A. C.; Crews, C. M. Induced Protein Degradation: An Emerging Drug Discovery Paradigm. Nat. Rev. Drug Discov. 2017, 16 (2), 101-114. https://doi.org/10.1038/nrd.2016.211.

(6) Maniaci, C.; Ciulli, A. Bifunctional Chemical Probes Inducing Protein-Protein Interactions. Curr. Opin. Chem. Biol. 2019, 52, 145-156. https://doi.org/10.1016/j.cbpa.2019.07.003.

(7) Gadd, M. S.; Testa, A.; Lucas, X.; Chan, K.-H.; Chen, W.; Lamont, D. J.; Zengerle, M.; Ciulli, A. Structural Basis of PROTAC Cooperative Recognition for Selective Protein Degradation. Nat. Chem. Biol. 2017, 13 (5), $514-521$. https://doi.org/10.1038/nchembio.2329.

(8) Rees, D. C.; Congreve; Murray, C. W.; Carr, R. Fragment-Based Lead Discovery. Nat. Rev. Drug Discov. 2004, 3 (8), 660-672. https://doi.org/10.1038/nrd1467.

(9) Erlanson, D. A.; Davis, B. J.; Jahnke, W. Fragment-Based Drug Discovery: Advancing Fragments in the Absence of Crystal Structures. Cell Chem. Biol. 2019, 26 (1), 9-15. https://doi.org/10.1016/j.chembiol.2018.10.001.

(10) Erlanson, D. A.; Braisted, A. C.; Raphael, D. R.; Randal, M.; Stroud, R. M.; Gordon, E. M.; Wells, J. A. Site-Directed Ligand Discovery. Proc. Natl. Acad. Sci. 2000, 97 (17), 9367-9372. https://doi.org/10.1073/pnas.97.17.9367.

(11) Sijbesma, E.; Hallenbeck, K. K.; Leysen, S.; de Vink, P. J.; Skóra, L.; Jahnke, W.; Brunsveld, L.; Arkin, M. R.; Ottmann, C. Site-Directed Fragment-Based Screening for the Discovery of Protein-Protein Interaction Stabilizers. J. Am. Chem. Soc. 2019, 141 (8), 3524-3531. https://doi.org/10.1021/jacs.8b11658.

(12) Wolter, M.; Valenti, D.; Cossar, P. J.; Levy, L. M.; Hristeva, S.; Genski, T.; Hoffmann, T.; Brunsveld, L.; Tzalis, D.; Ottmann, C. Fragment-Based Stabilizers of Protein-Protein Interactions through Imine-Based Tethering. Angew. Chem. Int. Ed. 2020, 59 (48), 21520-21524. https://doi.org/10.1002/anie.202008585.

(13) Kathman, S. G.; Statsyuk, A. V. Covalent Tethering of Fragments for Covalent Probe Discovery. MedChemComm 2016, 7 (4), 576-585. https://doi.org/10.1039/C5MD00518C.

(14) Jahnke, W.; Erlanson, D. A.; de Esch, I. J. P.; Johnson, C. N.; Mortenson, P. N.; Ochi, Y.; Urushima, T. Fragment-toLead Medicinal Chemistry Publications in 2019. J. Med. Chem. 2020, 63 (24), 15494-15507. https://doi.org/10.1021/acs.jmedchem.0c01608. 
bioRxiv preprint doi: https://doi.org/10.1101/2022.02.23.481635; this version posted February $24,2022$. The copyright holder for this preprint (which was not certified by peer review) is the author/funder, who has granted bioRxiv a license to display the preprint in perpetuity. It is made available under aCC-BY-ND 4.0 International license.

(15) Heightman, T. D.; Berdini, V.; Braithwaite, H.; Buck, I. M.; Cassidy, M.; Castro, J.; Courtin, A.; Day, J. E. H.; East, C.; Fazal, L.; Graham, B.; Griffiths-Jones, C. M.; Lyons, J. F.; Martins, V.; Muench, S.; Munck, J. M.; Norton, D.; O'Reilly, M.; Palmer, N.; Pathuri, P.; Reader, M.; Rees, D. C.; Rich, S. J.; Richardson, C.; Saini, H.; Thompson, N. T.; Wallis, N. G.; Walton, H.; Wilsher, N. E.; Woolford, A. J.-A.; Cooke, M.; Cousin, D.; Onions, S.; Shannon, J.; Watts, J.; Murray, C. W. FragmentBased Discovery of a Potent, Orally Bioavailable Inhibitor That Modulates the Phosphorylation and Catalytic Activity of ERK1/2. J. Med. Chem. 2018, 61 (11), 4978-4992. https://doi.org/10.1021/acs.jmedchem.8b00421.

(16) Murray, C. W.; Verdonk, M. L.; Rees, D. C. Experiences in Fragment-Based Drug Discovery. Trends Pharmacol. Sci. 2012, 33 (5), 224-232. https://doi.org/10.1016/j.tips.2012.02.006.

(17) Denis, J. D. S.; Hall, R. J.; Murray, C. W.; Heightman, T. D.; Rees, D. C. Fragment-Based Drug Discovery: Opportunities for Organic Synthesis. RSC Med. Chem. 2021, 12 (3), 321-329. https://doi.org/10.1039/D0MD00375A.

(18) Ercolani, G.; Schiaffino, L. Allosteric, Chelate, and Interannular Cooperativity: A Mise Au Point. Angew. Chem. Int. Ed. 2011, 50 (8), 1762-1768. https://doi.org/10.1002/anie.201004201.

(19) Krbek, L. K. S. von; Schalley, C. A.; Thordarson, P. Assessing Cooperativity in Supramolecular Systems. Chem. Soc. Rev. 2017, 46 (9), 2622-2637. https://doi.org/10.1039/C7CS00063D.

(20) Wilcox, D. E. Isothermal Titration Calorimetry of Metal Ions Binding to Proteins: An Overview of Recent Studies. Inorganica Chim. Acta 2008, 361 (4), 857-867. https://doi.org/10.1016/j.ica.2007.10.032.

(21) Nevola, L.; Giralt, E. Modulating Protein-Protein Interactions: The Potential of Peptides. Chem. Commun. 2015, 51 (16), 3302-3315. https://doi.org/10.1039/C4CC08565E.

(22) Raingeval, C.; Cala, O.; Brion, B.; Le Borgne, M.; Hubbard, R. E.; Krimm, I. 1D NMR WaterLOGSY as an Efficient Method for Fragment-Based Lead Discovery. J. Enzyme Inhib. Med. Chem. 2019, 34 (1), 1218-1225. https://doi.org/10.1080/14756366.2019.1636235.

(23) Viegas, A.; Manso, J.; Nobrega, F. L.; Cabrita, E. J. Saturation-Transfer Difference (STD) NMR: A Simple and Fast Method for Ligand Screening and Characterization of Protein Binding. J. Chem. Educ. 2011, 88 (7), $990-994$. https://doi.org/10.1021/ed101169t.

(24) Castro, G. V. de; Ciulli, A. Estimating the Cooperativity of PROTAC-Induced Ternary Complexes Using 19F NMR Displacement Assay. RSC Med. Chem. 2021. https://doi.org/10.1039/D1MD00215E.

(25) Zhang, C.; Zhuo, Y.; Moniz, H. A.; Wang, S.; Moremen, K. W.; Prestegard, J. H.; Brown, E. M.; Yang, J. J. Direct Determination of Multiple Ligand Interactions with the Extracellular Domain of the Calcium-Sensing Receptor. J. Biol. Chem. 2014, 289 (48), 33529-33542. https://doi.org/10.1074/jbc.M114.604652.

(26) Krimm, I.; Lancelin, J.-M.; Praly, J.-P. Binding Evaluation of Fragment-Based Scaffolds for Probing Allosteric Enzymes. J. Med. Chem. 2012, 55 (3), 1287-1295. https://doi.org/10.1021/jm201439b.

(27) Gossert, A. D.; Jahnke, W. NMR in Drug Discovery: A Practical Guide to Identification and Validation of Ligands Interacting with Biological Macromolecules. Prog. Nucl. Magn. Reson. Spectrosc. 2016, 97, 82-125. https://doi.org/10.1016/j.pnmrs.2016.09.001.

(28) Pennington, K.; Chan, T.; Torres, M.; Andersen, J. The Dynamic and Stress-Adaptive Signaling Hub of 14-3-3: Emerging Mechanisms of Regulation and Context-Dependent Protein-Protein Interactions. Oncogene 2018, 37 (42), 5587-5604. https://doi.org/10.1038/s41388-018-0348-3.

(29) Stevers, L. M.; Sijbesma, E.; Botta, M.; MacKintosh, C.; Obsil, T.; Landrieu, I.; Cau, Y.; Wilson, A. J.; Karawajczyk, A.; Eickhoff, J.; Davis, J.; Hann, M.; O'Mahony, G.; Doveston, R. G.; Brunsveld, L.; Ottmann, C. Modulators of 14-3-3 Protein-Protein Interactions. J. Med. Chem. 2018, 61 (9), 3755-3778. https://doi.org/10.1021/acs.jmedchem.7b00574.

(30) Guillory, X.; Wolter, M.; Leysen, S.; Neves, J. F.; Kuusk, A.; Genet, S.; Somsen, B.; Morrow, J. K.; Rivers, E.; van Beek, L.; Patel, J.; Goodnow, R.; Schoenherr, H.; Fuller, N.; Cao, Q.; Doveston, R. G.; Brunsveld, L.; Arkin, M. R.; Castaldi, P.; Boyd, H.; Landrieu, I.; Chen, H.; Ottmann, C. Fragment-Based Differential Targeting of PPI Stabilizer Interfaces. J. Med. Chem. 2020, 63 (13), 6694-6707. https://doi.org/10.1021/acs.jmedchem.9b01942.

(31) De Vries-van Leeuwen, I. J.; da Costa Pereira, D.; Flach, K. D.; Piersma, S. R.; Haase, C.; Bier, D.; Yalcin, Z.; Michalides, R.; Feenstra, K. A.; Jiménez, C. R.; de Greef, T. F. A.; Brunsveld, L.; Ottmann, C.; Zwart, W.; de Boer, A. H. Interaction of 14-3-3 Proteins with the Estrogen Receptor Alpha F Domain Provides a Drug Target Interface. Proc. Natl. Acad. Sci. 2013, 110 (22), 8894-8899. https://doi.org/10.1073/pnas.1220809110.

(32) Wolter, M.; de Vink, P.; Neves, J. F.; Srdanović, S.; Higuchi, Y.; Kato, N.; Wilson, A.; Landrieu, I.; Brunsveld, L.; Ottmann, C. Selectivity via Cooperativity: Preferential Stabilization of the P65/14-3-3 Interaction with Semisynthetic Natural Products. J. Am. Chem. Soc. 2020, 142 (27), 11772-11783. https://doi.org/10.1021/jacs.0c02151. 
bioRxiv preprint doi: https://doi.org/10.1101/2022.02.23.481635; this version posted February 24, 2022. The copyright holder for this preprint (which was not certified by peer review) is the author/funder, who has granted bioRxiv a license to display the preprint in perpetuity. It is made available under aCC-BY-ND 4.0 International license.

(33) Denis, J. D. S.; Hall, R. J.; Murray, C. W.; Heightman, T. D.; Rees, D. C. Fragment-Based Drug Discovery: Opportunities for Organic Synthesis. RSC Med. Chem. 2021, 12 (3), 321-329. https://doi.org/10.1039/D0MD00375A. 
bioRxiv preprint doi: https://doi.org/10.1101/2022.02.23.481635; this version posted February 24, 2022. The copyright holder for this preprint (which was not certified by peer review) is the author/funder, who has granted bioRxiv a license to display the preprint in perpetuity. It is made available under aCC-BY-ND 4.0 International license.
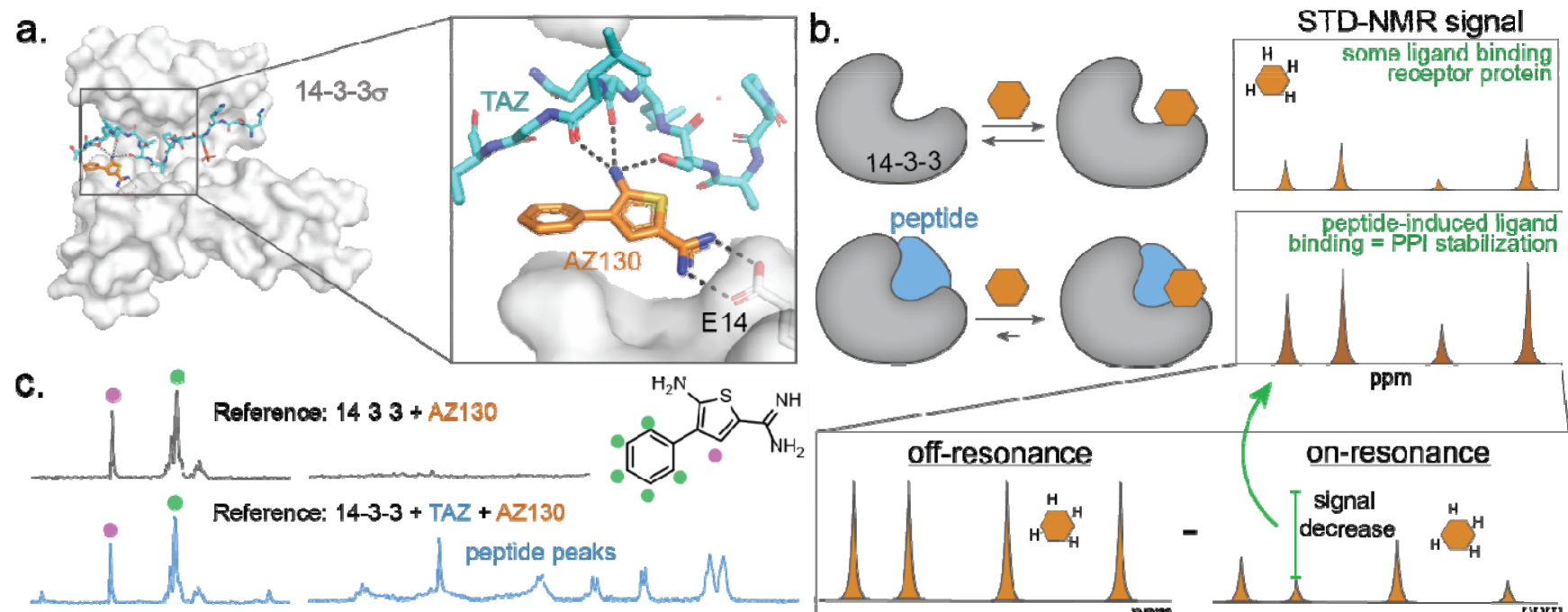

STD-NMR: $14-3-3+A Z 130$
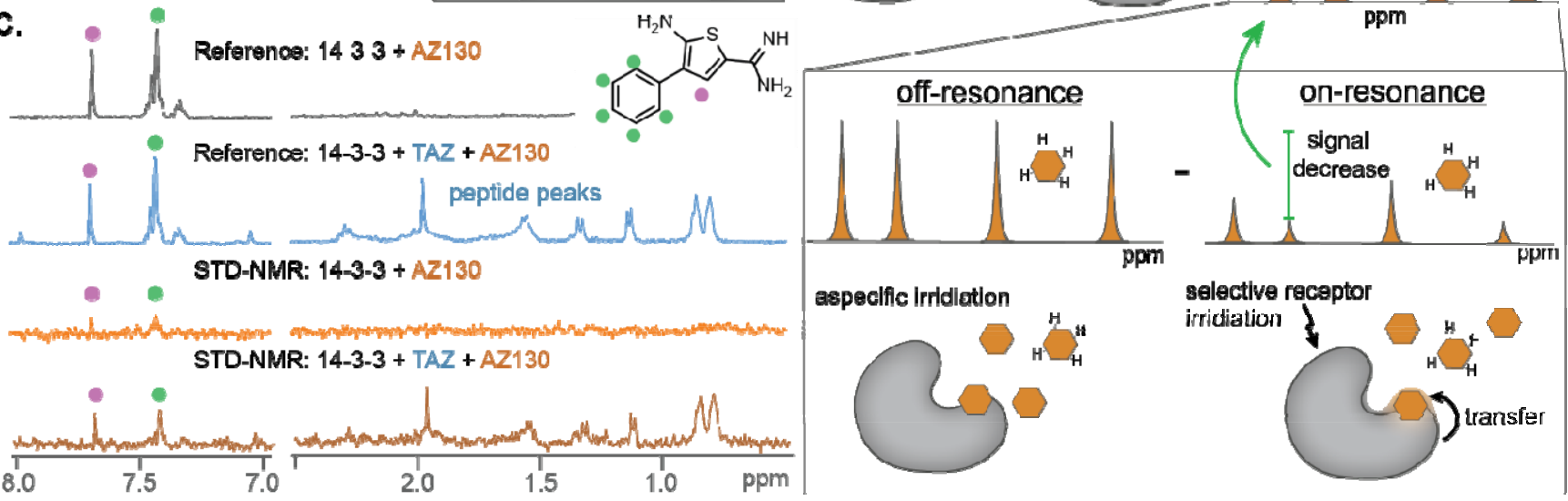

Figure 1 Detection of cooperative fragments by STD NMR. a. X-ray crystal structure of AZ130 in complex with 143-3 $/$ /TAZ peptide (PDB:6RHC). An enlargement of the 14-3-3/TAZ/AZ130 interface is shown in the grey box. 14-3-3 (grey) is depicted with Van Der Waals surface; TAZ peptide (cyan) is shown as a stick model; AZ130 (orange) is shown as a stick representation; polar interactions are depicted as black dashed lines. $\mathbf{b}$. Schematic representation of enhanced STD signal due to ternary complex formation between the 14-3-3 (grey), partner peptide (blue) and fragment (orange). The bottom panel depicts a cartoon representation of how an STD NMR spectrum (off-resonance - onresonance spectrums) is derived, which is more pronounced in the case of the ternary complex. c. Reference and STD NMR spectra of $300 \mu \mathrm{M} \mathrm{AZ130}$ with $10 \mu \mathrm{M}$ 14-3-3 $\sigma$ in the absence or presence of $100 \mu \mathrm{M}$ TAZ-peptide in PBS (50 mM $\mathrm{NaH}_{2} \mathrm{PO}_{4} / \mathrm{Na}_{2} \mathrm{HPO}_{4} \mathrm{pH} 7.5,150 \mathrm{mM} \mathrm{NaCl}, 10 \% \mathrm{D}_{2} \mathrm{O}$ ). 

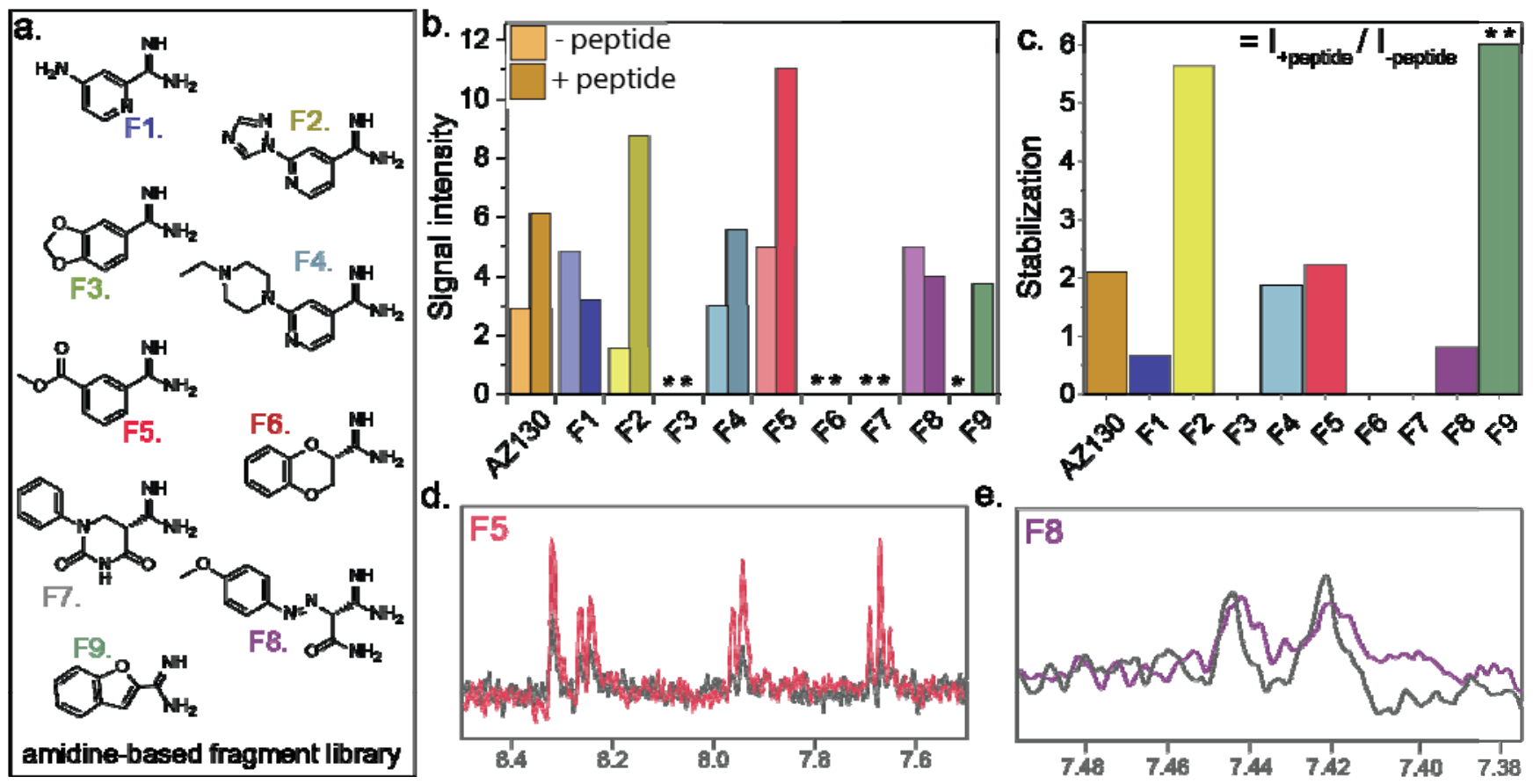

Figure 2 Initial fragment screening against TAZ. a. Focused library of small molecule amidine analogues. b. STD

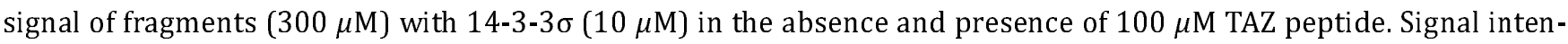
sity was calculated based on the peak intensity of an aromatic proton relative to the baseline of the STD NMR. * indicates no signal detected. c. Fold stabilization in signal upon addition of the peptide relative the binary experiment $\left(\mathrm{I}_{\text {+peptide }} / \mathrm{I}_{\text {-peptide }}\right) * *$ indicates stabilization cannot be well quantified, given the fragment does not bind to apo-14-3-3. d. Comparison of raw STD signal for F5 in the absence (black) and presence (red) of the TAZ binding partner. e. Comparison of raw STD signal for $\mathbf{F 8}$ in the absence (black) and presence (purple) of the TAZ binding partner. 
bioRxiv preprint doi: https://doi.org/10.1101/2022.02.23.481635; this version posted February 24, 2022. The copyright holder for this preprint (which was not certified by peer review) is the author/funder, who has granted bioRxiv a license to display the preprint in perpetuity. It is made available under aCC-BY-ND 4.0 International license.

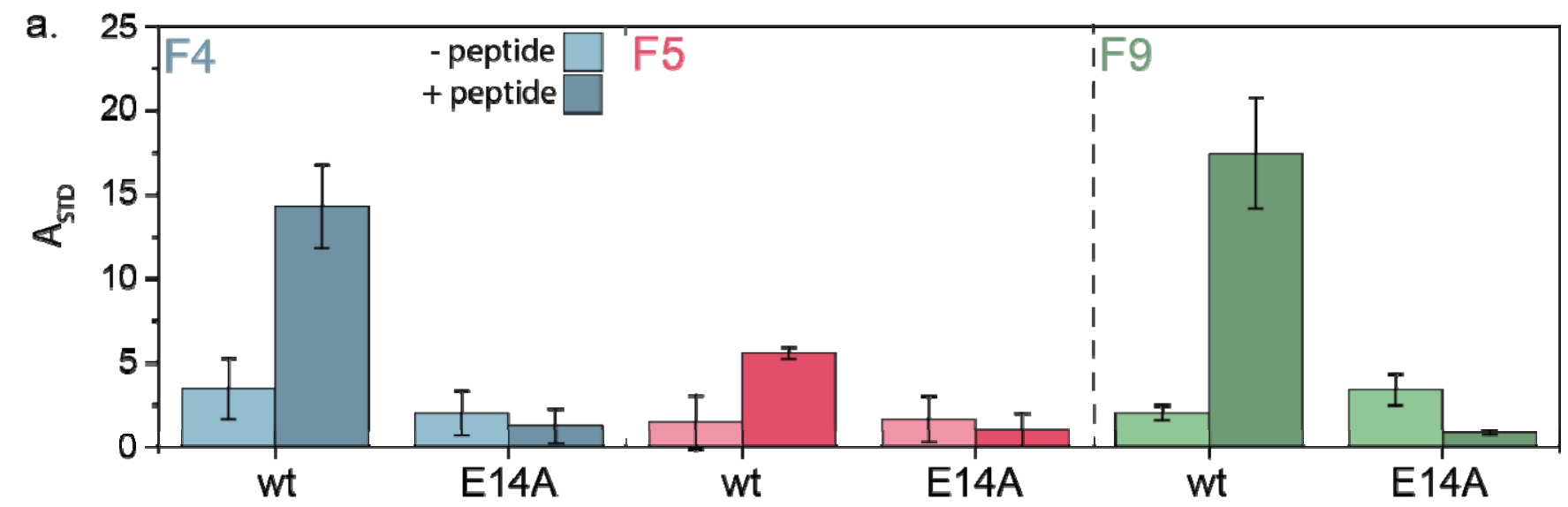

b.

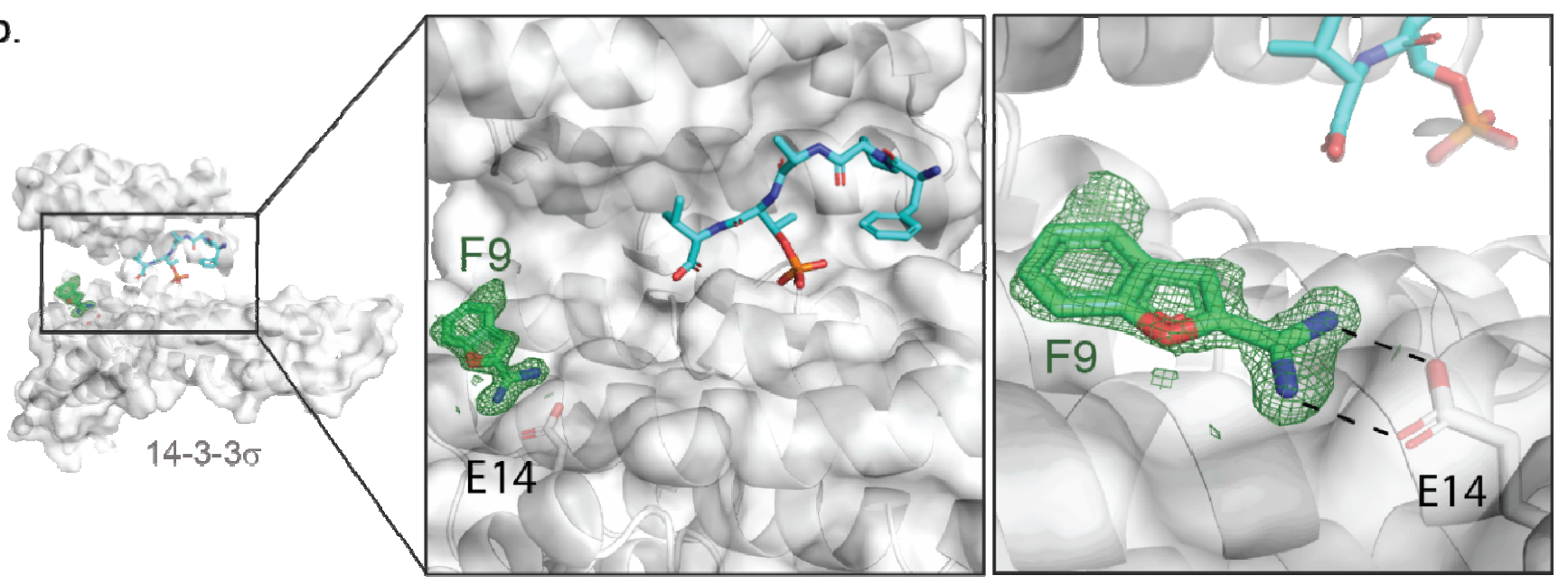

Figure 3 Validation of identified hit fragments. a. Comparison of enhancement of ASTD signals obtained for F4, F5 and F9 with and without TAZ peptide. For each fragment the activity using wildtype 14-3-3 $\sigma$ and the E14A mutant 14-3-30 are compared. Conditions: $5 \mathrm{mM}$ fragment, $100 \mu \mathrm{M}$ TAZ, $10 \mu \mathrm{M}$ 14-3-3. Error bars indicate the mean \pm SD from protons involved. b. Ternary X-Ray crystal structure of F9 in complex with 14-3-3 $\sigma$ and an ER $\alpha$ peptide. Within the black box is shown a close-up of the 14-3-3/ER $\alpha / F 9$ interface. 14-3-3 (grey) is depicted with Van Der Waals surface; $E R \alpha$ peptide (cyan) is shown as a stick model; F9 (green) is shown as a stick representation; polar interactions are depicted as black dashed lines. 2Fo-Fc electron density maps are contoured at 10. PDB: 702J 


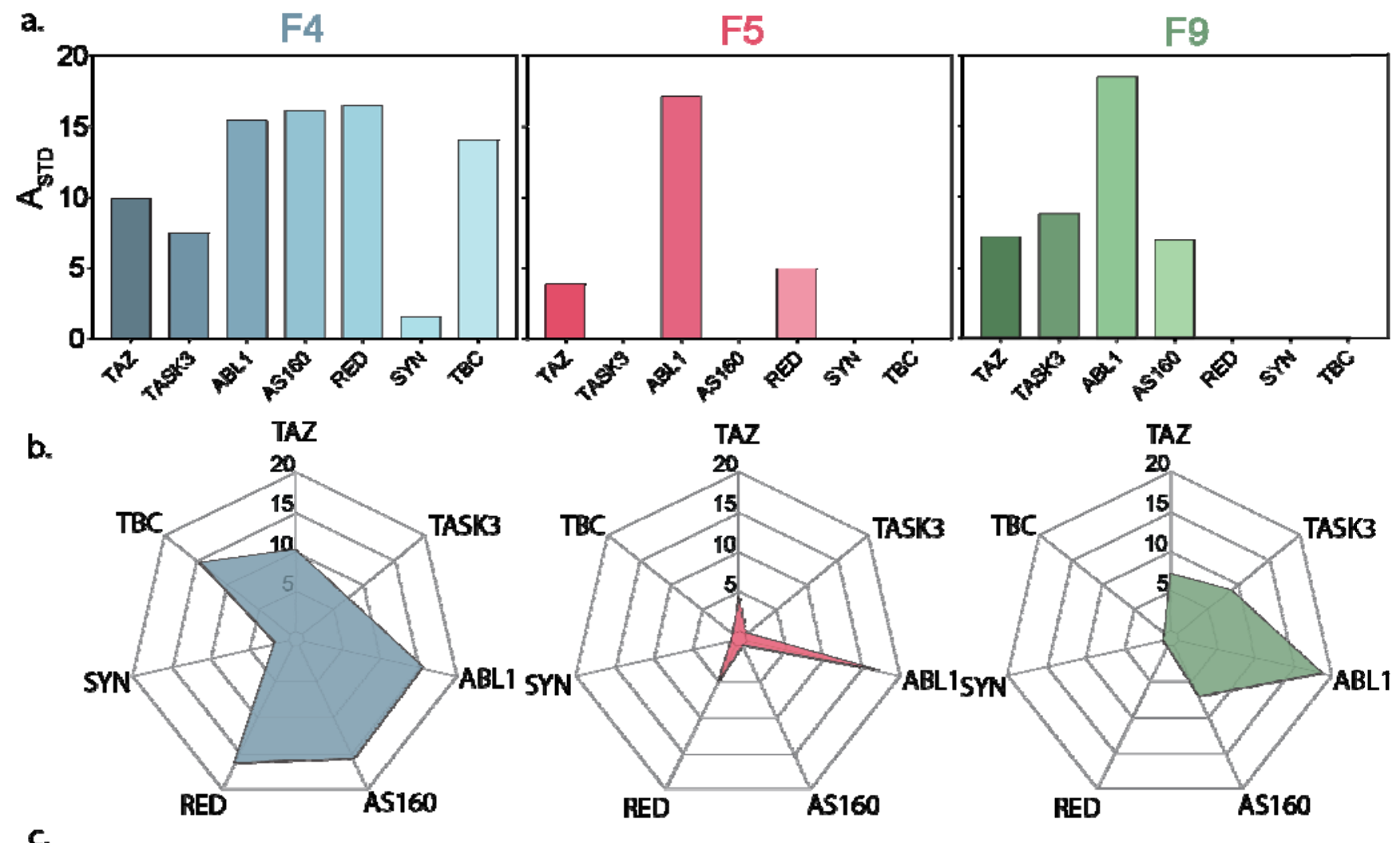

c.
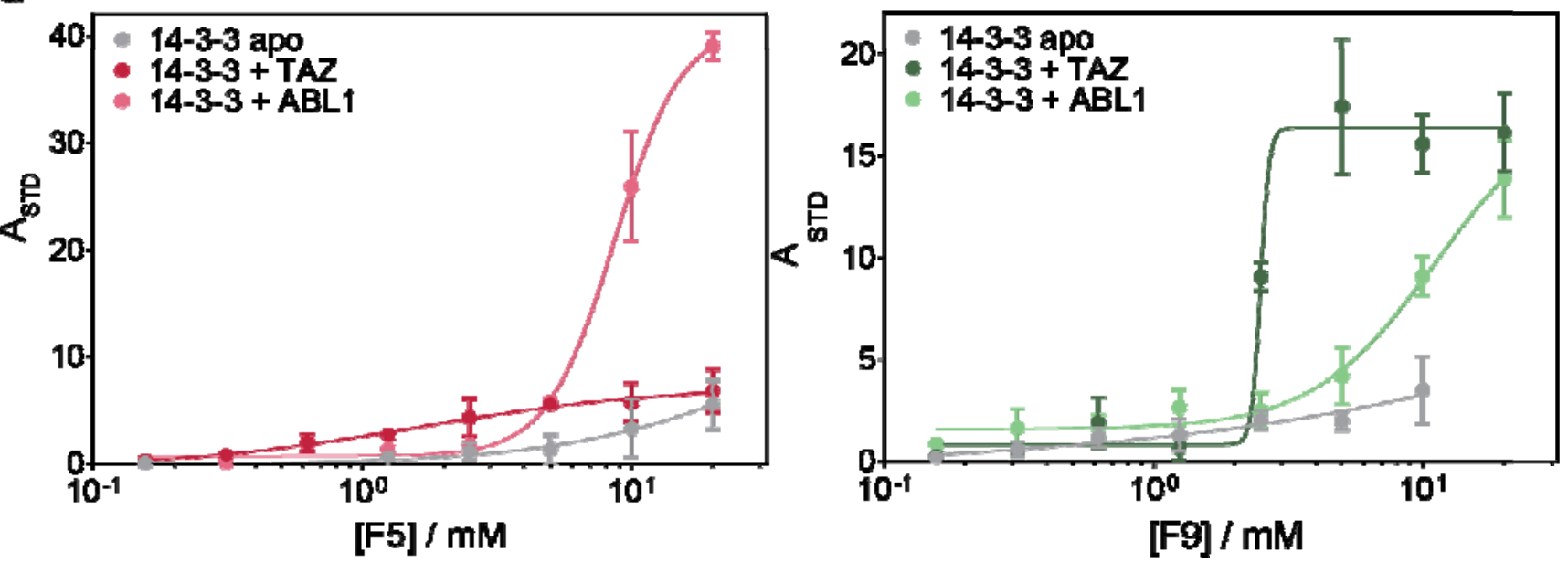

Figure 4 14-3-3 binding epitope selectivity screening panel. a. Bar chart representation of $A_{S T D}$ signal for F4, F5 and F9 in co-presence of various 14-3-3 binding peptides. Conditions: $5 \mathrm{mM}$ fragment, $100 \mu \mathrm{M}$ peptide, $10 \mu \mathrm{M}$ 14-3$3 \sigma$. b. Radar plot representing the selectivity profile of each fragment. c. Dose response of fragments F5 \& F9 to apo 14-3-3 $\sigma$ and 14-3-3 $\sigma$ in the presence of TAZ or ABL1. Error bars indicate the mean \pm SD from protons involved. 